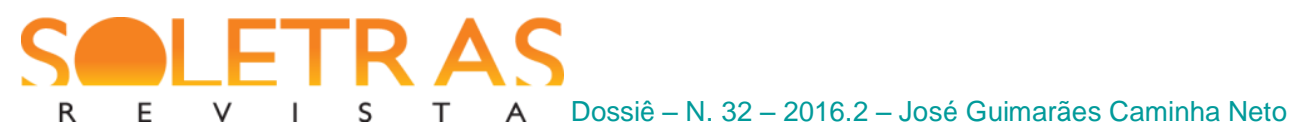

\title{
Calçada da fome: sobre os anjos e os mortos no Passeio da Glória
}

\author{
José Guimarães Caminha Neto ${ }^{1}$
}

Universidade do Estado do Rio de Janeiro

Resumo: Nesta reflexão sobre ontologias visuais, transita-se entre as fotografias antigas de pessoas provavelmente já mortas e o mercado vivo das ruas do Rio de Janeiro, notadamente no bairro da Glória, onde se observa o trabalho dos trapeiros numa área conhecida como “calçada da fome". É nesse espaço intertextual/intermidial que a cidade transforma-se num palco no qual se descortinam os modos de sobrevivência do flâneur e do passante, do trapeiro e do colecionador, e de tantos outros personagens criados por Walter Benjamin (1892 - 1940) e pela poesia de Charles Baudelaire (1821 - 1867). Esse movimento, que conecta em seu trajeto sujeitos, fotografias, artes plásticas, a cidade e suas ruínas, segue os sinais da "iluminação profana" proposta por Benjamin em $O$ Surrealismo - $O$ último instantâneo da inteligência europeia (1929). Por isso, a cidade é vista como um tableau vivant e aqueles artigos ali espalhados, objetos reunidos e ressignificados, formam o labirinto da memória e mapa contemporâneo da própria metrópole.

Palavras-chave: Walter Benjamin. Fotografia. Memória. História Social. Medium-dereflexão

"Método deste trabalho: montagem literária. Não tenho nada a dizer. Somente a mostrar. Não surrupiarei coisas valiosas, nem me apropriarei de formulações espirituosas. Porém, os farrapos, os

\footnotetext{
${ }^{1}$ Graduado em Comunicação Social (UERJ), especialista em Midia, Opinião Pública e Estratégia Política (IUPERJ), mestre em Teoria da Literatura (UFPE) e doutorando em Literatura Comparada (UERJ). Desenvolveu pesquisa na Itália, com bolsa da Capes, sob a orientação das Professoras Dra. Carlinda Fragale Pate Nuñez (UERJ) e da professora Dra. Valentina Valentini (Università di Roma La Sapienza) sobre os conceitos de Pathosformel, de Aby Warburg, e de imagem dialética, de Walter Benjamin, aplicando-os ao teatro de Bertold Brecht e ao cinema de Pippo Delbono.
} 
resíduos: não quero inventariá-los, e sim fazer-lhes justiça da única maneira possível: utilizando-os”. (Walter Benjamin, Passagens, N1a,8) ${ }^{2}$

\section{Situando a questão}

A compreensão da modernidade pelo poeta Charles Baudelaire (1821-1867), por parte de Walter Benjamin, vai resultar em dois grandes ensaios ${ }^{3}$ nos quais a imagem do poeta francês será a senha para Benjamin desenvolver os conceitos de choque e aura. $\mathrm{O}$ primeiro, enfatiza os esbarrões e múltiplos estímulos recebidos pelos transeuntes das grandes cidades, que fragmentam a percepção no ambiente da metrópole. O segundo discute, entre outras questões, um fenômeno observado na natureza e na arte que se caracteriza pela "inacessibilidade", "autenticidade" e "originalidade" dos objetos e da sua recepção. Neste, Sobre alguns temas em Baudelaire, Benjamin afirma: "Se considerarmos que as imagens emergentes da mémoire involuntaire se distinguem pela aura que possuem, então a fotografia tem um papel decisivo no fenômeno do "declínio da aura"” (BENAJMIN: 1994, pág. 139), dedução perturbadora, porque antecipa uma polêmica hoje central, para a abordagem da arte fotográfica. Se, por um lado, fotografar se tornou um hábito onipresente e os "fotoaditos" estão em toda parte, por outro, a facilidade em fazer e reproduzir instantâneos, segundo a intuição benjaminiana, reduziria a capacidade de desenvolver a imaginação - um dos sintomas da perda da aura.

$\mathrm{Na}$ crise da experiência tradicional da recepção da obra de arte, o filósofo alemão encontra lugar para pensar as relações do homem com o mundo contemporâneo. Sintomático, pois, que esse homem que vai perdendo a capacidade de narrar a partir da modernidade e se submete ao ritmo frenético da metrópole, passe a vestir-se de negro, como que vivenciando um longo trabalho de luto: "Desde a Monarquia de Julho, o preto e o cinza começaram a predominar nos trajes masculinos" (BENJAMIN:1994, p. 76), Essa "tristeza eterna", nas palavras de Baudelaire citadas por Benjamin em Paris do Segundo Império, é, segundo o poeta francês, a "expressão da alma pública representada numa imensa procissão de gatos pingados" (Ibidem) ${ }^{4}$.

\footnotetext{
${ }^{2}$ Valemo-nos da edição organizada por Willi Bolle (BENJAMIN: 2006, p.502).

${ }^{3}$ Em Paris do Segundo Império (1938), Benjamin vislumbra uma conexão entre o antigo e o presente, travestido de novo, que tem em comum um futuro de ruínas; já em Sobre alguns temas em Baudelaire (1939), choque e experiência se relacionam por meio da aprendizagem.

4 "Gatos pingados", de acordo com a tradução de José Carlos Martins Barbosa e Hemerson Alves Batista são “indivíduos que acompanhavam, com tocha ou archote, os enterros a pé” (BENJAMIN: 1994, p. 99).
} 
Os transeuntes enlutados que outrora acompanhavam o féretro, nos dias de hoje se postam, parados, junto aos vendedores de quinquilharias, em posição de respeito e humildade em relação a essa multidão que passa diariamente pelas ruas e, muitas vezes, não percebe que está sendo observada. Estão dispostos no chão, nas fotografias ${ }^{5}$ em preto e branco cuidadosamente arranjadas pelos trapeiros: junto ao silêncio sepucral daqueles retratos, nos quais se pode ver a "aparição única de uma coisa distante, por mais próxima que ela esteja" (BENJAMIN: 1994, p.170), está o olhar no qual ainda resiste a aura, acenando "pela última vez na expressão fugaz de um rosto, nas antigas fotos" (BENJAMIN: 1994, p. 174). Quem vela por eles são os trapeiros, totens urbanos e entesouradores do lixo social.

Este ensaio propõe uma reflexão a partir de fotografias não apenas encontradas, mas buscadas por passantes do comércio de rua, expostas no chão, em ruas de grande movimento, no Rio de Janeiro; fotografias que têm o seu mercado, inclusive de arte, pois se emancipam, justamente através do olhar desarmado dos passantes, de sua condição de mercadoria barata à de objeto com valor estético. Tal abordagem é possível através da conjugação de dois dispositivos teóricos: a fundamentação decorre da filosofia da história produzida por Walter Benjamin, sua mirada humanizadora de tudo o que discrepa, no plano da vida social, e de suas ideias proféticas ligadas à fotografia; a abordagem é intermidial, muito embora não se coloquem textualidades em conexão a partir das mídias consensualmente conhecidas. De fato, a peculiar intermidialidade aqui exercida segue a "iluminação profana" (profane Erleuchtungen ${ }^{6}$ ) sugerida na epígrafe, ao priorizar, em detrimento das "apropriações de formulações espirituosas", tableaux vivants da paisagem social contemporânea, cenas do cotidiano no turbilhão da metrópole. Enfim, flashes da sociedade de consumo articulados com textualidades fotográficas, a exemplo do que fez o próprio filósofo das Passagens.

\section{Paisagem social e fotografia}

\footnotetext{
${ }^{5}$ Cinema e fotografia, cada um a seu modo e por suas capacidades de reprodução, contribuem para a memória discursiva voluntária. Mas, se o cinema traz na sua dinâmica o declínio da capacidade de retribuir o olhar, como observa Benjamin em A obra de arte na era de sua reprodutibilidade técnica (1994, p. 165), o fracionamento do gesto da pessoa fotografada possibilita, para a prosperidade, um momento épico, no fluxo vital de quem vive cotidiano póstumo. O retrato deixa de ter qualquer valor artístico ou comercial, quando trata de pessoas anônimas, mas mantém o interesse pelo momento perdido e nunca vivido por aquele que o olha.

${ }^{6}$ A expressão aparece no ensaio $O$ Surrealismo - O último instantâneo da inteligência europeia (BENJAMIN: 2011, p. 23).
} 
Nas ruas inseguras do bairro carioca da Glória, mendigos e moradores de rua,

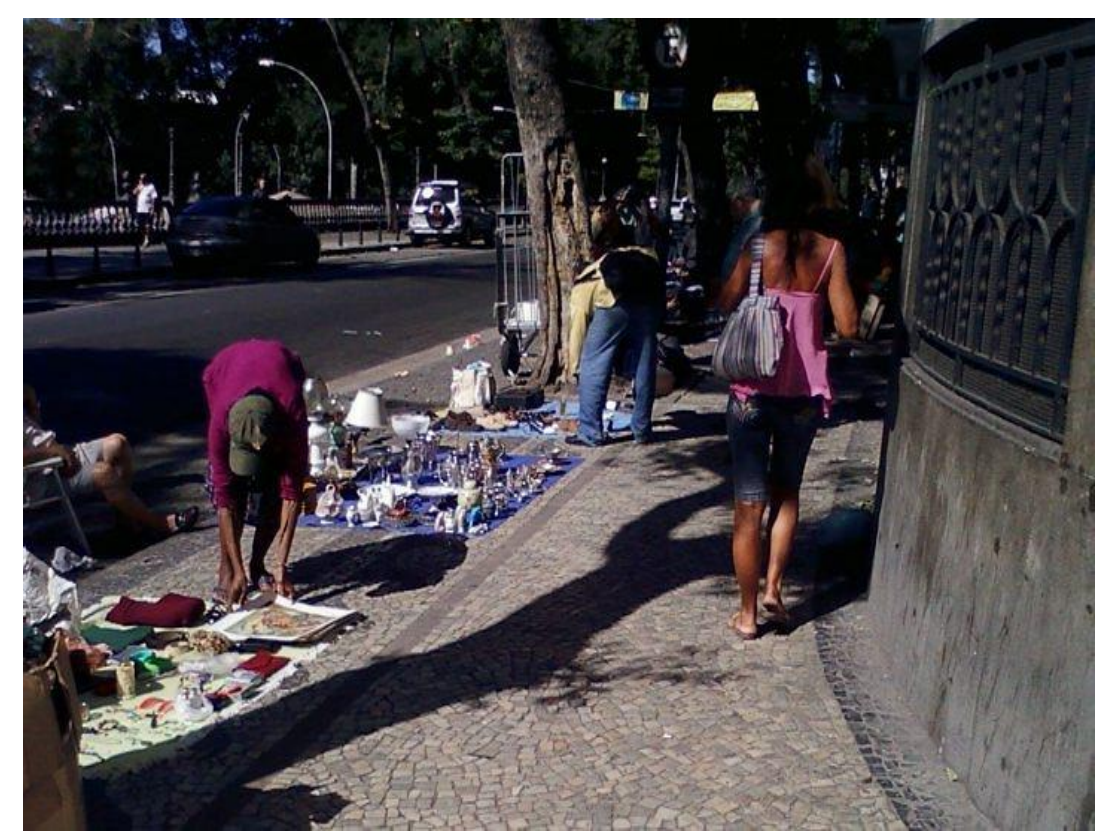

Fig. 1 - Trapeiros da Rua da Gloria e suas vitrines sobre o chão

"caçadores" de papéis, recolhem do lixo fotos antigas de pessoas anônimas para revendê-las. De quem são aquelas imagens fotografadas e sobre o que elas falam? Rastro, vestígio, fragmento, ausência presente; imagens que colocam o transeunte no caminho da reminiscência (Fig. 1) Uma fotografia antiga é também o passaporte para um lugar transformado pela memória. Reproduz um agora marcado pela ambivalência do presente e do passado.

Aquelas imagens do outrora convidam a um despertar; convocam o caminhante a se deter e sair do fluxo do consumo sonâmbulo algum tipo de reparação. O transeunte olha para trás, tal qual o Angelus Novus, o anjo da História de que fala Walter Benjamin na tese IX em Sobre o Conceito de História (BENJAMIN: 2011, pp. 222-232), que é empurrado pela tempestade do progresso, mas, solidário, não deixa de olhar para trás e recapitular o drama dos vencidos. O querubim, cuja imagem se desdobra na figura de homens engravatados, professoras, profissionais liberais, travestis e toda sorte de gente, esse novo bárbaro é ele mesmo uma ruína, resto de vivências anteriores. As imagens-túmulos convidam à contemplação, permitem a livre associação e evidenciam a confluência de tempos. De acordo com o tabu das direções, se "olhar para frente é desvendar o futuro e possibilitar a revelação, (...) para trás é o regresso ao passado, às hamartiai, às faltas, aos erros, é a renúncia ao espírito e à verdade" (BRANDÃO: 2015, p.151). 
O olhar do anjo-transeunte cai. Ele repete o mesmo gesto condenável da mulher de Lot que, do alto da montanha, mira atrás e assiste à destruição das cidades de Sodoma e Gomorra, desobedecendo a ordem divina e sendo, por isso, transformada em estátua de $\mathrm{sal}^{7}$. O anjo pode ser um monstro, já que é considerado "um cúmplice menor do diabo ou um enviado miraculoso de Deus, funesto presságio de sua cólera ${ }^{8}$. Testemunha da onipotência dos céus e mensageiro da desgraça sobre a Terra" (COURTINE: 2006, p. 375). Um ser preso à sua natureza melancólica que se sente indubitável e eternamente atraído pelo desejo de voltar, porque ele não vê outra via de felicidade que não seja a do retorno ${ }^{9}$.

Se o capitalismo é uma nova religião, como escreve Benjamin no fragmento de 1921 - em que defende a ideia de que o sistema econômico está "a serviço da resolução das mesmas preocupações, aflições e inquietações a que outrora as assim chamadas religiões quiseram oferecer resposta" (LÖWY: 2013, pág. 21) -, este anjo perdeu a conexão com o divino: deixa-se levar pela promessa do progresso e pelo culto à mercadoria. Ele olha, distraído e apressado, os pequenos objetos, tentando encontrar entre eles algo valioso: a promessa da libertação.

Não são apenas as quinquilharias, as revistas antigas, conjuntos de chá incompletos e pratos antigos e rachados que retardam o trajeto diário do anjo a caminho do trabalho ou das compras. As preocupações "surgem da angústia provocada pela situação sem saída de cunho comunitário, não de cunho individual-material” (BENJAMIN: 2013, p. 24),

\footnotetext{
${ }^{7}$ Entre os mensageiros da ira de Deus estão aqueles anjos que, em visita a Sodoma e Gomorra, avisam da destruição das cidades apenas à família de Lot: "Havendo-os tirado fora, disse um deles: escapa-te, salva a tua vida; não olhes para trás, nem te detenhas em toda essa planície. Escapa-te para os montes, para que não pereças" (Gn, 19:17). Mas a mulher de Lot olhou para trás e foi transformada numa estátua de sal (Gn, 19:26). Atualizando o gesto neste contexto, aos olhos do progresso não existe lugar nem há tempo para se apiedar dos mortos.

${ }^{8} \mathrm{O}$ caráter ambivalente do anjo, que J-J. Courtine apresenta na Histoire du Corps (2006), é, de fato, assustadora. Entre os mensageiros da ira de Deus estão aqueles anjos que, em visita a Sodoma e Gomorra, anunciam a destruição das cidades à família de Lot: "Havendo-os tirado fora, disse um deles: escapa-te, salva a tua vida; não olhes para trás, nem te detenhas em toda essa planície. Escapa-te para os montes, para que não pereças" (Gn, 19:17). Mas a mulher de Lot olhou para trás e foi transformada numa estátua de sal (Gn., 19:26). Atualizando o gesto no contexto atual, aos olhos do progresso não existe lugar, nem há tempo, para se apiedar dos mortos.

${ }^{9}$ Na segunda versão do hermético ensaio Angesilaus Santander, de 1933, Benjamin escreve sobre a criação dos anjos de acordo com tradição da Kabbalah: Deus cria anjos para que eles cantem diante do seu trono e logo depois desapareçam. Para o melancólico Benjamin, o "anjo se parece com tudo aquilo de que ele foi obrigado a separar-se" (SCHOLEM: 2007, p. 24). O anjo segue o seu destino inexorável, na crença de que, não estando só, encontrará a felicidade: "Ele quer a felicidade: o contraste no qual o êxtase da unidade, da novidade, do ainda não vivido, é unida àquela beatitude da repetição, da recuperação, do vivido. Por isso ele não tem esperança de novidade por outro caminho que não seja aquele do retorno, quando conduz com ele um novo ser humano" (SCHOLEM: 2007, pág. 24. Tradução nossa). Na edição consultada: "Egli vuole la felicità: il contrasto in cui l'estasi dell'unicità, della novità, del non ancora vissuto, è unita a quella beatitudine della ripetizione, del recupero, del vissuto. Perciò egli non ha speranza di novità per altra via che non sia quella del ritorno, quando conduce seco un nuovo essere umano".
} 
pois uma linha delicada e quase imperceptível separa o trapeiro da mendicância e da vadiagem: "Uma condição tão sem saída é culpabilizadora", escreve Benjamin (id., ib.). De um lado, a miséria do que se oferece e se anuncia naquele que tenta manter viva a crença na salvação; do outro, o remorso pela recusa em consumir o que não tem valor de mercado. $\mathrm{O}$ anjo citadino olha com desdém para aqueles que não são economicamente ativos.

No bazar a céu aberto, os retratos sem legendas parecem ainda mais órfãos. Eles exigem um nome, mas não necessariamente aqueles que lhes foram dados pelos arquivos oficiais. Eles reivindicam uma vida e, do transeunte, pegam emprestada a memória compartilhada no passeio público; a imagem surrupia um pouco da história de outrem no momento em que realiza a troca: "Quem é visto, ou acredita estar sendo visto, revida o olhar. Perceber a aura de uma coisa significa investi-la do poder de revidar o olhar” (BENJAMIN: 1994, p. 139-140). A foto até então estranha do parente perdido, do amigo morto, dos examantes... vira trombadinha da memória, sequestradora do tempo presente que toma de assalto quem a encontra para levá-la para outras ficções no culto das recordações de parentes distantes e mortos. A moldura do tableau que se estende sobre a calçada, o que o cerca, não se constitui de ângulos retos e evoca muitas outras imagens em movimento. O desenho do painel, com seus intervalos e sobreposições, é um mapa, face surrealista da cidade na qual o transeunte caminha entre as dobraturas do tempo.

Se a ruína é a memória inscrita na paisagem, no Passeio da Glória, no Rio de Janeiro, ela se perfila na verticalidade do casario e nos rostos fotografados em branco e preto que se espalham pelo chão como reticências que o progresso deixou para trás. Contemplar as imagens que jazem sobre tapetes encardidos na Rua do Passeio, conhecida também como "calçada da fome", por reunir um grande número de trapeiros e catadores, é um exercício de rememoração e, por que não, uma possibilidade de construção histórica ${ }^{10}$ que se manifesta na experiência cotidiana. As fantasmagorias ${ }^{11}$ impelem a evitar o momento do despertar, pois, em vez de rememorar, é mais fácil esquecer.

\section{A metrópole como medium-de-reflexão}

\footnotetext{
10 "Rememorar" tem aqui o sentido de aniquilar, destruir as impressões. No sentido alegórico, o verbo não está ligado à memória, mas ao gesto alquímico que desintegra para recriar para além da beleza, aproximando o procedimento mais do esquecimento do que da memória.

${ }^{11}$ Trata-se de um conjunto das imagens representativas do real produzidas pela sociedade que, depois, passa a vêlas não mais como uma ilusão, pois elas ganham vida própria, independente da vontade e do pensamento dessa mesma sociedade. Transformado em fantasmagoria, o objeto se move alheio à vontade da sociedade que o produziu.
} 
A nostalgia ou a tristeza diante de uma fotografia antiga permite ao observador perceber que ela traz embutida uma promessa, uma imagem de felicidade ${ }^{12}$. Para Walter Benjamin, embora a fotografia represente também uma perda, uma ausência, essa imagem evoca as possibilidades não realizadas no passado, que se dirigem ao que "foi" e ao que "poderia ter sido": "O passado traz consigo um índice misterioso que nos impele à redenção" - índice de positividade. Esse "encontro secreto, marcado entre as gerações precedentes e a nossa" é a prova de que somos todos portadores de uma "frágil força messiânica à qual o passado tem (uma) pretensão" que não pode ser descartada (BENJAMIN: 2011, p. 222).

A partir do texto Escavando e Recordando, presente na obra Rua de mão única (BENJAMIN: 1995, pp. 239-240), e de algumas considerações do mesmo Benjamin relacionadas à fotografia e à montagem, em Magia e Técnica, arte e política (2011), é possível fazer uma aproximação com a noção de 'acontecimento', formulada por Foucault (1984). Esta é uma proposta tão problemática e complexa quanto a própria definição de 'acontecimento' forjada pelo filósofo, no artigo O que são as Luzes? (FOUCAULT: 2008, pp. 335-351). Para ele, 'acontecimento' seria um espaço temporal em que se suspende a habitual evidência de compreensão, abrindo uma fenda na realidade. $\mathrm{O}$ 'acontecimento' compromete a lógica e o senso comum, no sentido que problematizar o que o ser humano é e o mundo em que ele vive.

Se o tempo do 'acontecimento' é o de um presente descontínuo, que dissolve o passado e anuncia um devir, como descortiná-lo na sociedade do espetáculo em que estamos inseridos? Como distingui-lo, se a lógica corrente nos faz acreditar que, para um fato ganhar o status de 'acontecimento', é preciso que a mídia o transforme em notícia? A experiência do choque, ligada à modernidade e à melancolia pela perda da experiência autêntica - perda da aura - é um acontecimento no arco do pensamento benjaminiano. Fantasmagórica, individual e fragmentária, a experiência do choque ganha materialidade poética em Baudelaire.

A figura alegórica do trapeiro, que vive do refugo da metrópole, sobreviveu aos tempos e às diferentes culturas. Agora, ele é o catador que reutiliza o lixo nas ruas do centro do Rio, dando algum aproveitamento ao que sobra do desenfreado consumo dos tempos modernos. Ao fotógrafo, artífice de uma poética do olhar, não passam despercebidos os

\footnotetext{
12 A “imagem da felicidade", que é citada por Walter Benjamin na tese 2 de Sobre o conceito da história e que acompanha a representação do passado, dá-se a ver nesse encontro casual com aqueles fantasmas de papel mostrados nas fotografias "tingidas pelo tempo": "Não nos afaga, pois, levemente, um sopro de ar que envolveu os que nos precederam? Não ressoa nas vozes a que damos ouvidos um eco das que estão, agora, caladas? E as mulheres que cortejamos não tem irmãs que jamais conheceram?” (BENJAMIN: 2011, pág. 222).
} 
significados latentes do drama social que o turbilhão das cidades abafa, assim como saltava aos olhos de Benjamin o discurso da modernidade, imiscuído na trama social parisiense de fins do século XIX. As correlações entre as duas cenas públicas, distantes, mas congêneres, não param por aí. Ensejam uma correlação intermidial inusitada - entre o olhar que produz imagens poéticas através de palavras e o olhar recondicionado pelos meios técnicos, a partir da popularização das câmeras fotográficas, no século XX, que produzem "imagens visuais pensantes" (Denkbilder $\left.{ }^{13}\right)$.

Benjamin identifica semelhanças entre Baudelaire e a figura do trapeiro, pois ambos realizam seus "negócios", enquanto os burgueses dormem: "os poetas encontram o lixo da sociedade nas ruas, e no próprio lixo o seu assunto heróico" (BENJAMIN: 1994, p. 78). Mas, assim como os trapeiros, o poeta deve sair à cata de palavras usadas e de coisas poéticas, nomeadas como coisas outras: restos, pedaços, peças, lixo... O gesto do transeunte, semelhante ao do poeta, parece ser o de dar um novo uso às coisas. Ele há de encontrar poesia em meio à história.

Concomitante ao processo da rememoração, constrói-se uma relação entre o passado e o presente. O pedestre segue, agora, os passos de um flanador. Não aqueles trilhados pelo literato que vai ao mercado na Paris da segunda metade do século XIX, mas os passos de um transeunte do início do século XXI, fascinado pela cultura de massa embora sem tempo para a contemplação. Esse flâneur não passeia por avenidas de calçadas largas, em que os monumentos são valorizados pelo projeto urbanístico arrojado de uma Paris revitalizada. No espaço urbano do Rio de Janeiro, os monumentos em bronze são saqueados. Pilham-se tampas de boeiros, roubam-se mesmo a feiosa fiação aérea de um sistema de iluminação ultrapassado, saqueiam até depósitos do governo para levar vigas de toneladas de aço. Aquele flâneur, que se deparava com as fantasmagorias das "exposições universais" e se dedicava, despreocupado, às longas caminhadas, agora é um consumidor apressado e inseguro que esbarra, com olhar cabisbaixo, em livros usados, utensílios domésticos, roupas de defuntos e fotografias de desconhecidos pelo chão. Nestas, muitos rostos anônimos o olham, como se o reconhecessem.

Poderíamos admitir as categorias criadas por Walter Benjamin como 'acontecimentos', na linha que rege o senso comum da crítica e do pensamento ocidentais. $A$ Obra das Passagens, que Benjamin idealizou em 1927 e no qual ele trabalhou até a morte

\footnotetext{
13 O termos aparece como título de um capítulo, em Rua de mão única ("Imagens do pensamento"), e também de um dos ensaios (BENJAMIN: 1994, pp. 267-272).
} 
(1940), é uma reflexão sobre seu próprio método de trabalho, elaborado em fichários. Nele, o autor almeja uma síntese utópica entre progresso tecnológico e qualidade de vida em que a “escrita de transformação internacional", de grande mobilidade e irradiação, pode visar a transformações históricas. Benjmain vê na metrópole um medium-de-reflexão e expressão possível para essa nova escrita - crítica em relação ao discurso desgastado da propaganda e da comunicação do seu tempo. O flâneur, a massa ou a mercadoria são alguns dos traços da modernidade europeia que assomam à condição de categorias úteis para a construção do seu discurso ${ }^{14}$. Com esse olhar, a escrita da memória continua recolhendo citações, colecionando imagens e fragmentos de outros autores e campos artísticos.

Se a marca histórica do objeto não está apenas no tempo em que ele está inscrito, mas também no solo remexido, é importante observar que as imagens às quais nos referimos não mais se encontram sobre móveis solenes e em locais de destaque nas casas, tampouco em exposições. A sua montagem sobre o tapete encardido obriga-nos a fazer associações individuais.

Esses objetos são um convite à distração ou à contemplação? Se expostos na rua, num espaço urbano pouco nobre, a massa humana de espectadores apressados entre um compromisso e outro fará com que as imagens ali associadas sejam tragadas, no empuxo de seu ritmo, segundo os critérios de distração e recolhimento. As imagens que integram o décor de passantes, na galeria também itinerante, "representam um contraste que pode ser assim formulado: quem se recolhe diante de uma obra de arte mergulha dentro dela e nela se dissolve, como ocorreu com um pintor chinês, segundo a lenda, ao terminar seu quadro. A massa distraída, pelo contrário, faz a obra de arte mergulhar em si, envolve-a com o ritmo de suas vagas, absorve-a em seu fluxo" (BENJAMIN: 2001, pág. 193).

\footnotetext{
2007, 93 ), faz um estudo pormenorizado sobre o método benjaminiano.

14 Em Leituras de Walter Benjamin, o ensaio "Medium-de-Reflexão", de Willi Bolle (SELIGMANN-SILVA: 
Ao retirar as fotografias dali e colocá-las, ainda que no chão, no tempo de uma

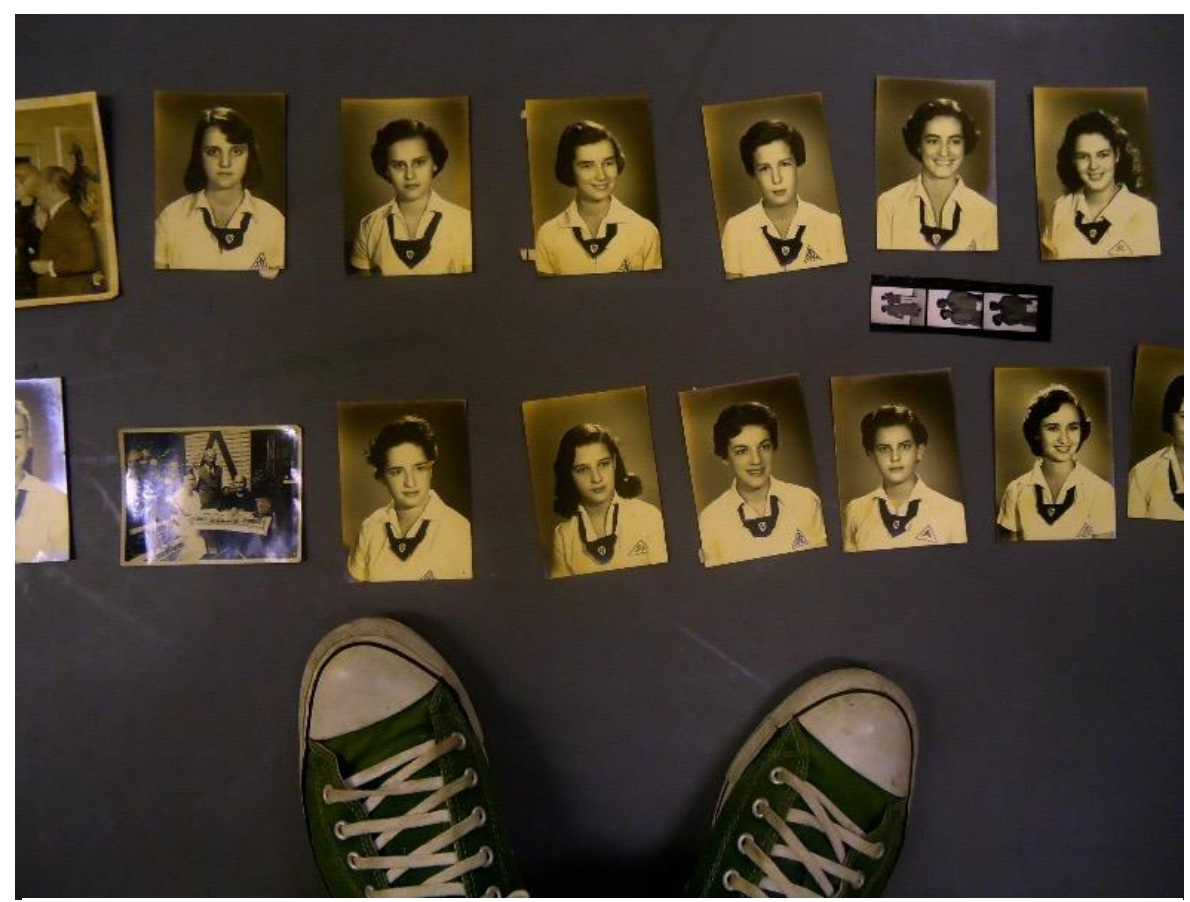

Fig. 2 - Exposição de fotografias no espaço SESC de Copacabana, em novemhro de 9014

vernissage, as mesmas imagens farão com que o público mergulhe nelas, num processo que Benjamin designa como "recolhimento" (Fig. 2). Enquanto o olhar caminha sobre a tela que se estende, podemos recortar as imagens que se referem aos ritos de passagem. Essa opção pode parecer óbvia, na busca por acontecimentos, posto que eventos como casamentos, formaturas, batizados e velórios são singulares e escapam à rotina. Por outro lado, esses ritos existem para normatizar a vida social e estão ligados a aspectos mais estáveis e duradouros e, portanto, se distanciam da ideia de ruptura.

Mas a história não se faz de forma tão simplista. Há ainda um outro lugar para reflexão, proposto por Benjamin. Nele, a tradição é reduzida a imagens e passa a integrar um espaço lúdico - como se aquele tapete de bugingangas metálicas, plásticas e louças desencontradas se transformasse numa tela de cinema, ou numa obra cubista, em que a colagem de elementos díspares abalam a aparência de totalidade. Os vultos humanos ali estendidos em fotografias, entre aqueles esqueletos da indústria, lançam olhares impiedosos a quem se atreve a mirá-los. Nesta presença de outra subjetividade ali configurada, o sujeito ganha sobrevida. 
$\mathrm{Na}$ imagem que guarda a lembrança de um evento e que, no na rua ou na

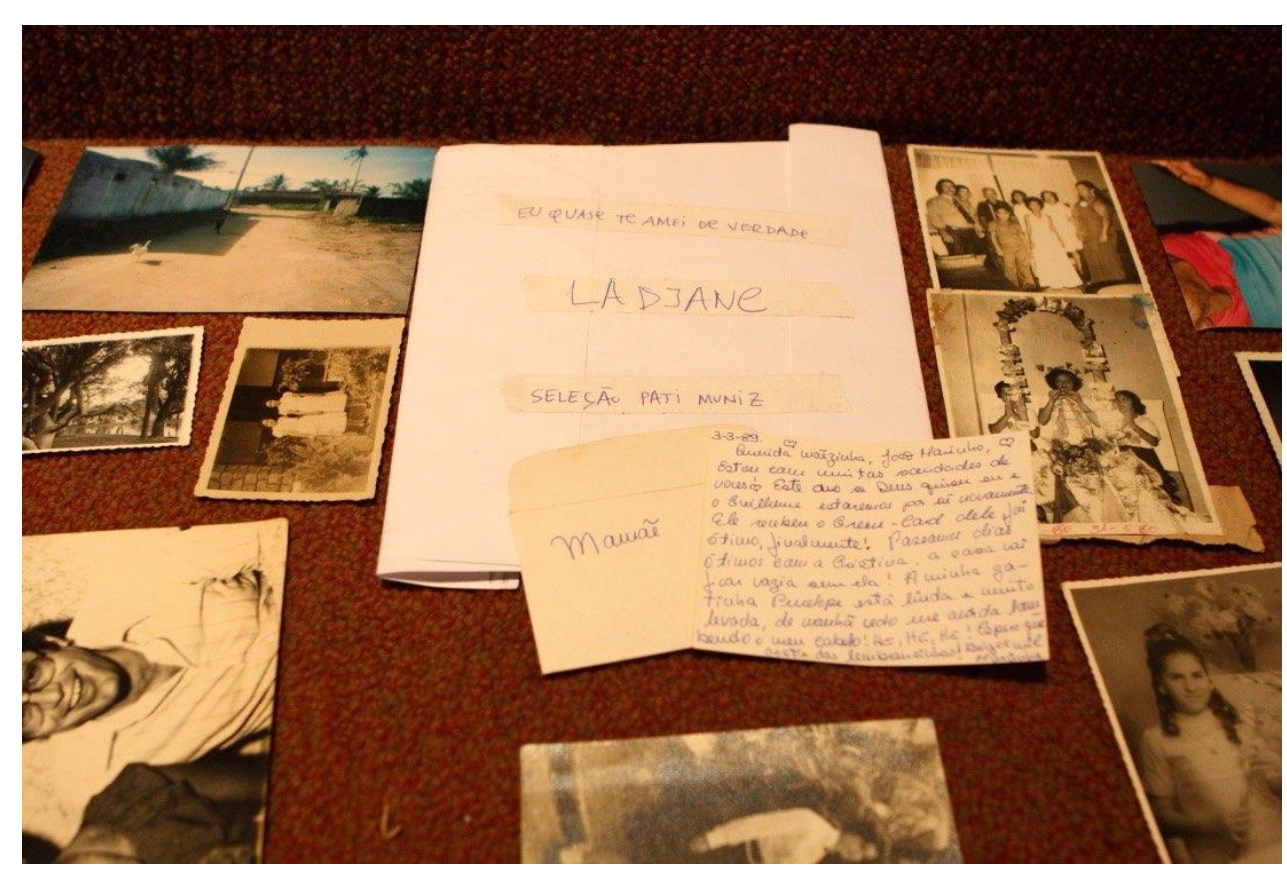

Fig. 3- Ainda segundo Benjamin, o rosto humano, a última trincheira de resistência ao valor do culto, tem no retrato um semblante da saudade "consagrada aos amores ausentes ou defuntos", em que a "aura acena pela última vez na expressão fugaz

galeria de arte, se revela na ausência do protagonista, o paradoxo de algumas fotografias, a ausência no rasto, resiste na singularidade do rosto humano, o qual, mesmo infinitamente reproduzível, mantém a autenticidade pelo contato (Fig. 3): "Eis provavelmente o que Walter Benjamin não soube ver no seu famoso texto sobre a reprodutibilidade das imagens: que o elemento do contato permaneça uma garantia de unicidade, de autenticidade e de poder portanto de aura - para além da sua própria reprodução” (DIDI-HUBERMAN, 2008: pág. $72,73)$.

Rostos anônimos, retratos de papel e em número reduzido de reproduções, que resistem ali, depois de serem jogados no lixo por herdeiros que não enxergaram valor algum na fotografia do defunto ou do velho agora exilado na casa geriátrica. As fotos em preto e branco ficam durante muito tempo no Passeio, porque são uma alegoria dos que não alcançaram status na sociedade do espetáculo: anônimos, fracassados, esquecidos e desprezados que viram mercadoria, esperança para aqueles que são refugo da sociedade. Portanto, mesmo quando exumadas do lixo, através da publicidade que lhes confere a 
construção alegórica ${ }^{15}$, essas imagens estão longe do Olimpo hollywoodiano. Como que por contágio, os fotografados, tanto os antigos quanto os atuais que os decriptam do lixo onde jazem, são anônimos que se encontram no território marginal da calçada, onde podem ser pisoteados, e que só foram salvos da incineração pela ação do catador. Não se trata de artistas

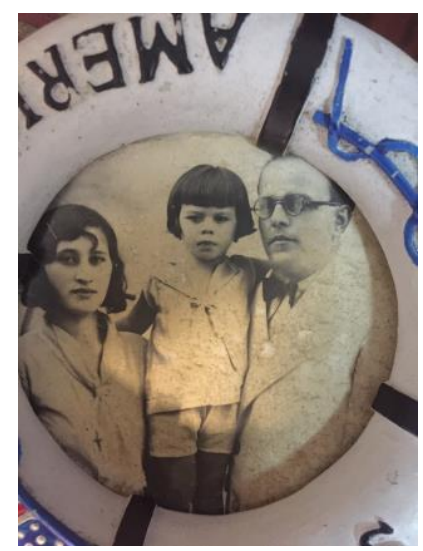

famosos ou estrelas de cinema, que tem lugar garantido no espaço de evasão neoarcaico da cultura industrial ${ }^{16}$. Mas naqueles rostos anônimos há algo de estranho e de novo que já havia chamado a atenção de Walter Benjamin (Fig. 4):

No tensaio Pequena história da fotografia (1934), Benjamin reconhece algo que não se reduz ao gênio artístico do autor da imagem, mas os traços de alguém que reclama a sua identidade na fotografia e que não quer desaparecer:

Depois de mergulharmos suficientemente fundo em imagens assim, Fig. 4: Viajantes: família percebemos que também aqui os extremos se tocam: a técnica mais exata pode dar às suas kriaç̃ées um val đar mágico que um quadro nunca mais terá

\footnotetext{
15 Sem escapar ao sentido usual de representação concreta de uma ideia abstrata, a alegoria aqui assinalada, em sua indigência social, reforça uma profundidade em geral negada à figuração alegórica. Em sua particularidade, os dejetos humanos que pairam, fotografados (seres reminiscentes), se reproduzem, diferidos, nos párias sobre as calçadas que, também desacatando os que foram alguém um dia, despudoradamente os "catam". Nesta série de paralelismos, sentidos subterrâneos se acasalam (BERISTÁIN: 2011: pág. 25) com o sentido do contexto social que as fotos, por sua vez, alegorizam: a publicidade adquirida aprofunda o sentido de empório de morte de onde tanto uns quanto outros foram exumados

${ }^{16}$ No volume I, Cultura de Massas no século XX, Edgar Morin (2000) explica esse neoarcaísmo como um dispositivo do qual se serve a indústria cultural para se dirigir ao anthropos comum, o homem arcaico que cada um traz em si mesmo. Além disso - e mais pertinente ao pensamento aqui exposto - é um espaço de evasão em que a tradição é cooptada pela lógica consumista.
} 
para nós. (...) o observador sente a necessidade irresistível de procurar nessa imagem a pequena centelha do acaso, do aqui e agora com o qual a realidade chamuscou a imagem, de procurar o lugar imperceptível em que o futuro se aninha ainda hoje em minutos únicos, há muito extintos, e com tanta eloquência que podemos descobri-lo, olhando para trás (BENJAMIN, 2011, pag. 94).

Retomando as reflexões de Edgar Morin, vemos que os astros da nova configuração proposta pela indústria cultural impõem modelos de uma certa práxis para a vida privada que torna possível o mito de autorrealização. Talvez por isso, imagens de pessoas consagradas - ou bem sucedidas - de acordo com a mídia, dividem espaço por tão pouco tempo com os anônimos no passeio da Glória. Eles estão nas capas das revistas, cujo folhear abre-se em pequenas narrativas episódicas que colaboram na construção do mito. Será o transeunte anônimo quem rapidamente retirará o mito daquela configuração para restituir-lhe, por alguns trocados, a dignidade. O movimento na Rua do Passeio, cada vez mais intenso, é o de uma rua de mão dupla: do real para o imaginário e vice-versa. Ou ainda, contraditoriamente, movimento sincrônico de evasão e de integração.

O trapeiro divide espaço com mendigos, prostitutas e travestis para além dos limites da Glória. Onde o transeunte encontra um obstáculo, o colecionador procura o objeto do seu fetiche ${ }^{17}$. "Tem um rapaz que passa por aqui de 15 em 15 dias. Ele gosta de foto de artista. Tem outra que só quer saber de Ângela Maria”, comenta Sérgio Coutinho, "expositor" de 61 anos que estende o seu tapete ao lado numa das ruas que dão acesso ao Teatro Municipal, no bairro da Cinelândia (Rio de Janeiro). Walter Benjamin, um visionário, diz que “na verdade não está longe o dia em que haverá mais folhas ilustradas que lojas vendendo caças ou aves" (2011, p. 104).

Ao reutilizar imagens antigas, salvando-as do seu fim iminente, o colecionador lhes possibilita outras ficcionalidades. Na sua missão salvadora, cabe a ele, com sua paixão, retirar das coisas o caráter puramente mercantil, mitigando a perda da experiência. É o que fazem artistas como Rosângela Rennó, mineira que se dedica a inventariar fotos e slides de autores desconhecidos, além de recuperar câmeras e projetores analógicos, (re)criando meios e imagens e despertando no público uma sensação de estranhamento. Na mesma linha de

\footnotetext{
${ }^{17}$ Em $O$ capital, quando analisa os modos de produção e consumo na modernidade, Karl Marx nota que a mercadoria muitas vezes perde o valor real - mensurado pela quantidade de trabalho - para adquirir uma valoração irreal e um poder sobrenatural ou simbólico, virando objeto de culto.
} 


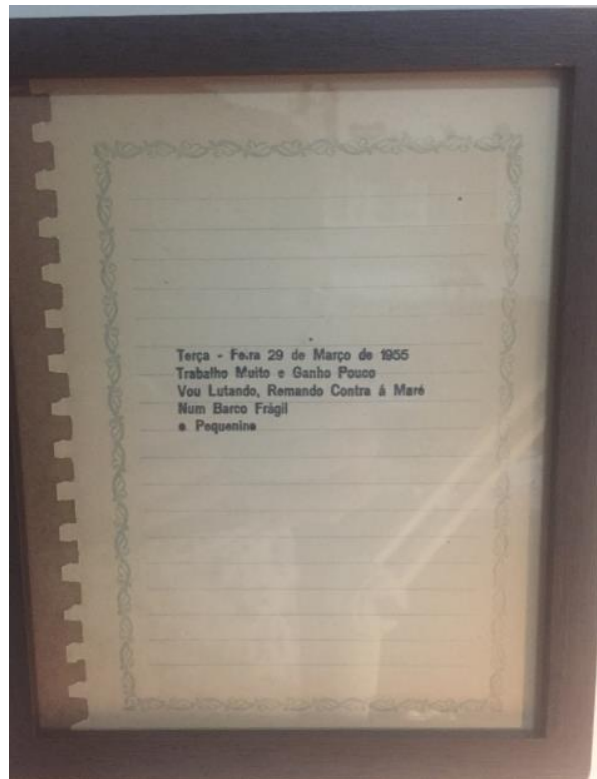

Fig. 5: Projeto plástico e teatral Osmarina Pernambuco não consegue esquecer, Casa Quintal das Artes Cênicas, Rio de Janeiro, 2016.

manufatura de imagens "ociosas", a carioca Keli Freitas, dramaturga e cenógrafa, criou um espetáculo teatral e uma série de quadros em carimbaria (Fig. 5) baseados nas frases recolhidas dos diários de sua avó, a dona de casa Maria Felix Pinheiro da Silva, morta aos 94 anos, moradora de Madureira, subúrbio do Rio.

\section{Mirando rasto atrás}

Ao parar no espaço da calçada, o transeunte detém-se no tempo e se remete ao mundo dos mortos e dos esquecidos. Na tentativa de colocar-se em contato com uma experiência autêntica, narrada por imagens documentais, submete-se à experiência do choque: outros consumidores apressados esbarram com ele, o celular toca, o mendigo pede dinheiro, o ambulante pede passagem.

Como bem disse Benjamin, na atividade da flânerie, os longínquos, sejam eles países ou épocas, irrompem na paisagem e no instante presente. $\mathrm{O}$ transeunte encara fixamente o rosto desconhecido ali exposto, reconhecendo-se e, através dele, à sua própria fragilidade. É como se o clic dado lá atrás ecoasse em outro tempo e em outro lugar. A metrópole, como mídia que se expressa e se pensa, interpela e se conecta, interage com suas memórias e seus atores. Uma intermidialidade sui generis avulta e "acontece" à sombra de 
indivíduos que circulam pelo cenário urbano. Fotografias, mais que documentos de um momento, provam-se dispositivos capazes de ativar conexões entre história social e artes visuais, paisagem humana e memória cultural, atores do presente e subjetividades do passado perene das imagens fotográficas.

Nesse painel ganha corpo o conceito da fantasmagoria. Na tentativa de tornar suportável a história arruinada, composta por cacos, o transeunte fetichiza retratos antigos, porque neles se encontra a marca sépia da aura. Se a ruína e a decadência têm marcas evidentes do tempo passado, pois são testemunhos de dias melhores, elas convidam a um exercício de memória no qual a consciência individual se reflete na potência da flâneurie, que vê as coisas de acordo com a sua conveniência.

O transeunte esquece, lembra, rememora e narra de acordo com a memória, pois o pensamento é também uma prática de montagem. Aqueles que passam pela calçada da fome participam, memo sem se dar conta, de uma sobreposição de tempo e espaço nos quais imagens paradas convivem com outras em movimento; em que as fotografias e o chafariz sem água são a senha de um tempo passado e de um presente onde personagens esquálidos sobrevivem do refugo de outras vidas.

O trapeiro tem a autoridade de organizar essa narrativa fúnebre, na qual alguns personagens repousam em covas coletivas e outras passam apressadas como defuntos em potencial, pois a vida, lenta produção do cadáver - como lembra Walter Benjamin em $O$ narrador, considerações sobre a obra de Nikolai Leskov -, tem naquele encontro fortuito um flerte épico com a sabedoria e a memória:

Assim como no interior do agonizante desfilam inúmeras imagens - visões de si mesmo, nas quais ele se havia encontrado sem se dar conta disso - assim o inesquecível aflora de repente em seus gestos e olhares, conferindo a tudo o que lhe diz respeito aquela autoridade que mesmo um pobre diabo possui ao morrer, para os vivos ao seu redor. $\mathrm{Na}$ origem da narrativa está essa autoridade. (BENJAMIN: 2011, pp. 207-208)

Os elementos que compõem esse tableau da vida real, montado em parte pelos trapeiros da calçada da fome, fazem lembrar um campo santo, pois as imagens dos mortos não estão só na superfície do cemitério, em estátuas, lápides, fotos e epitáfios. Estão nos sobreviventes, nos gestos quase inconscientes que lhes foram ensinados na infância e no 
cenário daquele passeio inglório por onde, tantas vezes, os mesmos vultos retratados passaram cheios de sonhos e desejos inconfessáveis.

De acordo com o pensamento benjaminiano, o índice histórico das imagens indica não apenas que elas pertencem a um determinado tempo, mas que elas atingem a legibilidade apenas num tempo determinado. É uma história não resolvida, passível de infinitas atualizações que não se realizam no registro da exposição linear do discurso e da fábula, mas tão somente da lógica do refugo consumista. A sua exposição é fragmentária, e a temporalidade da obra, pontual: todos os dias os trapeiros rearrumam o tableau- vitrine, obedecendo à dinâmica do consumo.

As fotos que passam a integrar outro contexto, livres da sua função original, são também um índice de maleabilidade do tempo. Assim, a história se recompõe em cacos de tempos heterogêneos, que desestabilizam os conceitos de verdade e memória. Sem dúvida, os meios de comunicação de massa influenciaram a percepção do homem e o seu posicionamento no mundo. A forte subjetividade que rege a época em que vivemos dá tamanha visibilidade ao sujeito, que isso acaba por privilegiar o "eu" no território de hegemonia simbólica que são os meios audiovisuais, como observa Beatriz Sarlo (2007, p. 38): "o testemunho, por sua auto-representação como verdade de um sujeito que relata sua experiência, exige não ser submetido às regras que se aplicam a outros discursos de intenção referencial, alegando a verdade da experiência, quando não a do sofrimento, que é justamente a que deve ser examinada". A espetacularização da vida privada e a reprodução da própria imagem talvez sejam formas de buscar reconhecimento e, ainda que por um viés não artístico mas puramente técnico, de vencer a morte.

A foto perdida ou jogada fora pelas gerações posteriores está agora num céu constituído de brinquedos quebrados, tesouras, moedas e talheres, bem no espaço limiar entre o lugar do transeunte e o do túmulo, o chão. O retrato repousa no território do despertar, entre o tempo da reencarnação - se resgatado pela rememoração do transeunte - ou do pó, enquanto o transeunte desaparece na multidão sem rosto e sem retrato.

O olhar é o mesmo do Angelus Novus, que inspirou Benjamin a escrever sobre o gesto de olhar para trás, numa tentativa de lembrar dos mortos e lhes fazer justiça: impelido para o progresso e voltado para um passado de ruínas e destruição, porque, olhando para trás, o transeunte esbarra consigo mesmo. $\mathrm{O}$ andar apressado não impede que o pensamento reconheça, naquele outro deitado no chão, a imagem na qual aparece o próprio futuro. É ali que o caminhar se detém por um instante: um memento mori que transforma o Passeio da 
R E V I S T A Dossiê - N. 32-2016.2 - José Guimarães Caminha Neto

Glória no cenário de uma dança macabra, e ao flâneur, sem asas, numa estátua de sal que compõe a paisagem de uma necrópole.

\section{Referências Bibliográficas}

BENJAMIN, Walter. Magia, Técnica, Arte e Política (Obras Escolhidas, vol. 1). Trad. Sérgio Paulo Rouanet. São Paulo: Brasiliense, 2011. . O capitalismo como religião. (org. Michael Lowy; trad. Nélio Schneider, Renato Ribeiro Pompeu). São Paulo: Boitempo, 2013.

- Passagens. Organização de Willi Bolle; tradução do alemão Irina Aaron. Belo Horizonte: Editora UFMG; São Paulo: Imprensa Oficial do Estado de São Paulo, 2006.

Rua de mão única. (Obras escolhidas, v. 2). Trad. Rubens Rodrigues Torres Filho e José Carlos Martins Barbosa. São Paulo: Brasiliense, 1995.

BUCK-MORSS, S., HANSEN, M. e SCHÖTTKER, D. Benjamin e a obra de arte

- Técnica, imagem, Percepção. (Trad. Marijane Lisboa e Vera Ribeiro). Rio de Janeiro: Contraponto, 2012.

BERISTÁIN, Helena. Diccionario de Retórica y Poética. México: Editorial Porrúa, 2001.

BOLLE, Willi. "Medium-de-Reflexão" in Seligmann-Silva, Márcio (org.) Leituras de Walter Benjamin. São Paulo: FAPESP: Annablume, 2007.

CARDOSO, Irene. Para uma crítica do presente. São Paulo: Editora 34.

COURTINE, Jean-Jacques (dir.). Histoire du corps. Vol. 3: Les mutations du regard. Le XXe siècle. Paris : Le Seuil, 2006.

DIDI-HUBERMAN, G., La ressemblance par contact - archéologie, anachronisme et modernité de l'empreinte. Collecion Paradoxe. Paris: Editions de Minu, 2008, FOUCAULT, Michel [1984]. “O que são as Luzes?”. Ditos e Escritos II: Arqueologia das Ciências e História dos Sistemas de Pensamento. Org. M. B. Motta. Trad. E. Monteiro. Rio de Janeiro: Forense Universitária, 2005. Pp. 335-351.

LÖWY, Michael. Walter Benjamin: aviso de incêndio - uma leitura das teses "Sobre o conceito de história”. Trad. Wanda Nogueira Caldeira Brant, trad. das teses: Jeanne Marie Gagnebin, Marcos Lutz Müller. São Paulo: Boitempo, 2010.

MORIN, Edgar. Cultura de Massas no Século XX: Neurose, Edição brasileira de O Espírito do Tempo, 9. Edição, Rio de janeiro: Forense Universitária, 1997. 
SARLO, Beatriz. Tempo Passado: cultura da memória e Guinada subjetiva. São Paulo: Companhia das Letras, 2007.

SCHOLEM, Gershom.Walter Benjamin e il suo angelo. Milano: Adelphi Edizioni, 2007

SELIGMANN-SILVA, Márcio (org.) Leituras de Walter Benjamin. 2 a edição, São Paulo: FAPESP, 2007.

\title{
Walk of hunger: about the angels and the dead on the sidewalk of Gloria
}

\begin{abstract}
In this reflection on visual ontologies, there is a transit between the old photographs of people probably already dead and the living market on the streets of Rio de Janeiro, notably in a residencial area named Gloria where the exposition of articles by rag man results in a well know place named "sidewalk hunger". Here, the intertextuals/intermidial spaces of the city are transformed into stage wherein it is possible to see the survival modes of the flaneur and the ragman, as well many other characters created by Walter Benjamin (1892 - 1940) and by the poet Charles Baudelaire (1821 - 1867). This movement that brings together in its way subjects, photography, plastic arts, the city and its ruins follows the signs of "profane illumination", expression that sparked in his essay Surrealism: the Last Snapshot of the European Intelligentsia (1929). Therefore, the city become a tableau vivant and those items and articles exposed in sidewalk are redefined in the labyrinth of memory as a map of contemporary metropolis itself.
\end{abstract}

Key-words: Walter Benjamin - Photography - Memory - Social History - Medium of Reflexion

Recebido em: 13 de outubro de 2016.

Aprovado em: 10 de dezembro de 2016. 